\title{
Personal, musical and social benefits of singing in a community ensemble: Three case studies in Melbourne (Australia)
}

\author{
D JOSEPH ${ }^{1}$ AND J SOUTHCOTT ${ }^{2}$
}

\begin{abstract}
Australia has a diverse, multilayered society that reflects its rich musical life. There are many community choirs formed by various cultural and linguistically diverse groups. This article is part of an ongoing project, Well-being and ageing: community, diversity and the arts (since 2008), undertaken by Deakin University and Monash University, that explores the cultural diversity within Australian society and how active music engagement fosters well-being. The singing groups selected for this discussion are the Skylarkers, the Bosnian Behar Choir, and the Coro Furlan. The Skylarkers and the Bosnian Behar Choir are mixed groups who respectively perform popular music from their generation and celebrate their culture through music. The Coro Furlan is an Italian male choir who understand themselves as custodians of their heritage. In these interpretative, qualitative case studies semi-structured interviews were undertaken and analyzed using Interpretative Phenomenological Analysis. In this approach there is an exploration of participants' understanding of their lived experiences. The analysis of the combined data identified musical and social benefits that contribute to participants' sense of individual well-being. Musical benefits occurred through sharing, learning and singing together. Social benefits included opportunities to build friendships, overcome isolation and gain a sense of validation. Many found that singing enhanced their health and happiness. Active music making in community choirs and music ensembles continues to be an effective way to support individuals, build community, and share culture and heritage.
\end{abstract}

Keywords. Music and positive ageing; community singing; cultural identity; well-being

\section{Introduction and background}

This article discusses community music and successful ageing in Australia where the ageing population creates challenges for the maintenance of well-being. Although there are differing definitions about what successful ageing might be, most researchers would agree that, "being socially connected, having good health, and having a positive subjective evaluation of one's life are important markers of optimal development" (Huxhold, Fiori \& Windsor, 2013, p. 13). Good health and well-being are becoming key issues in social discourse. Social

1. Dr. Dawn Joseph is a Senior Lecturer in music and education studies in the Faculty of Arts and Education, Deakin University, Melbourne, Australia. She researches, publishes and reviews in music education, teacher education, African music, multiculturalism and ageing in the Arts. dawn.joseph@deakin.edu.au

2. Dr. Jane Southcott is an Associate Professor in the Faculty of Education, Monash University, Australia. She is a narrative historian and a hermeneutic phenomenologist who researches community engagement with music, with a particular focus on positive ageing. jane.southcott@monash.edu 
engagement as part of health and well-being is more than simply occupying available time. For older people, regular social interactions are important sources of support and have been conceptualized in various ways, such as social integration, engagement, participation, networks, and connectedness (Heaven, et al., 2013).

Participation in social activities has been identified as crucial in successful ageing. Huxhold, Miche, and Schüz (2013, p. 366) note that a number of studies identify that "the level of activity engagement in general improves subjective well-being and health in older adults". For older adults, social activities are important and may function as a "buffer against negative effects of ageing" (Huxhold, Miche, \& Schüz, p. 366). Understanding the effect of the social interactions on the well-being of older adults is "important for the promotion of active ageing in the community" (Cramm, et al., 2012, p. 147) that is defined as "the continuing participation of older people in society ... in a manner that allows them to realize their potential for well being throughout their lives" (Cramm, et al., p. 143). There is a close association between the maintenance of active social relations and "better health outcomes and reduced mortality in later life" (Heaven, et al., 2013, p. 224). Social connections are important for individual wellbeing and "those with closer social relations tend to be more optimistic and healthier. Social relations also affect subjective well-being $\ldots$ by providing the individual with the opportunity for participation ... in a social context" (Huxhold, Miche, \& Schüz, 2013, p. 366). Conversely, a lack of social connectedness may have negative health outcomes. A lack of social connection may be understood by the individual as loneliness that is an unique and powerful negative predictor of well-being (Chen \& Feeley, 2014).

The experience of ageing can be affected by cultural backgrounds. Australia, a country of ongoing migration, comprises many different cultures, faiths, ethnicities and languages. Since the first British settlement in Sydney in 1788, Australia has been characterized by multilingualism (Clyne \& Kipp, 2006). This vibrant multilingualism is part of the diversity that forms a cultural mosaic comprised of immigrants who maintain many of the traditions of their home countries whilst simultaneously "embracing, to a greater or lesser extent, the new norms, values and practices of the adopted country" (Ashman, 2008, p. 7). Australia aspires to be a tolerant and inclusive society made up of people from many different backgrounds. Cultural diversity is a central feature of our national identity (Department of Foreign Affairs and Trade, 2011) and it is recognized that migration has always contributed to the social and economic fabric of the nation. According to the most recent census, there are more than twenty-three million resident Australians (Australian Bureau of Statistics 2013a). New Census data has revealed that almost a quarter (24.6 per cent) of Australia's population was born overseas and 43.1 per cent of people have at least one overseas-born parent and at least 200 languages spoken, thus Australia's multicultural landscape remains as diverse as ever (Australian Bureau of Statistics, 2013b).

Australia's population, like that of most developed countries, is ageing. According to the Australian Bureau of Statistics (2011), in the two past decades the proportion of the population aged 65 years and over has increased "from $11.1 \%$ to $13.6 \%$. During the same period, the proportion of population aged 85 years and over has more than doubled". This trend is expected to continue over the over the next two decades. The issues of ageing have been recognized as a National Priority by the Australian federal government. The Minister for Ageing at this time, the Hon. Mark Butler MP, asserted that, the Australian Government is committed to ensuring equitable access to high quality, culturally appropriate programs for older people from culturally and linguistically diverse backgrounds (Australian Government Department of Health and Ageing, 2012). There are six Australian states and two territories. 
Of these, the State of Victoria where this research was undertaken has the fourth oldest population.

Successful ageing involves maintaining well-being through actively engageing with life through the making and sustaining of relationships within community (Anetzberger, 2002). When older people engage in meaningful social engagement with others, there are observable positive health outcomes (Lally, 2009). The World Health Organization (WHO) (2012) confirms that population ageing is an inevitable and predictable global phenomenon. The WHO has identified that ageing populations demand increasing attention to the concept of active ageing that is a process of optimization of opportunities for participation, security and health to enhance quality of life (WHO, 2002). The WHO asserts that active ageing should allow people "to realize their potential for physical, social, and mental well-being throughout the life course and to participate in society according to their needs, desires and capacities, while providing them with adequate protection, security and care" (2002, p. 12). In this sense, 'active' refers to continuing participation in social, economic, and cultural aspects of life (WHO, 2002). Cultural aspects of life include engagement with the arts; active music making and sharing this music making with the wider Australian community is the focus of this discussion.

Active participation by older people in community music programs has many potential benefits and can improve their quality of life (Cohen, Bailey \& Nilsson, 2002). The benefits associated with older people singing encompass an enhanced sense of personal and social well-being as well as a range of identified psychological and physical outcomes (Clift \& Hancox, 2001; Skingley \& Bungay, 2010; Skingley, Clift, Coulton \& Rodriguez, 2011). Music participation in a singing group can offer social affirmation and opportunities for collaboration through which participants gain a sense of fulfilment, autonomy, empowerment and being valued by the community (Chené \& Sigouin, 1995; Sixsmith \& Gibson, 2007). This contributes to an overall sense of social cohesion, independence and resilience (Creech, et al., 2013a; Coffman, 2002b). Singing in a group can provide opportunities for people to combat negative feelings such as depression, loneliness and a sense of social isolation (Skingley \& Bungay, 2010; Escuder-Mollon, 2012; Creech, et al., 2013a). Participation in group singing provides a meeting place that can assist social relationships and networking (Skingley \& Bungay, 2010). Jacob, Guptill and Sumsion (2009) found that the participants in their study looked forward "to seeing their friends at choir practice each week and ... enjoy the social aspect of the choir" (p. 189). Shared music making can provide older singers with opportunities to remember and reconnect with their youth and that of their audiences (Southcott \& Joseph, 2013; Li \& Southcott, 2012). This connection can offer "some 'anchorage to life"' (Borglin et al., 2005, p. 205) as will be identified in the diverse singing groups discussed.

\section{Methodology}

This article discusses three case studies from a larger ongoing research project, Well-being and ageing: community, diversity and the arts in Victoria that began in 2008 and has been undertaken by academic researchers from two metropolitan Australian universities in Melbourne, Victoria (Deakin University and Monash University). The research project has entailed a number of case studies of individual visual and performing arts community organizations that cater for older people who remain active in their local communities. Ethical approval having been gained, three individual groups located via the networks of Community Arts Victoria and Multicultural Arts Victoria were contacted by a Research 
Assistant and invited to take part in the study. Data were gathered between 2008 and 2012 through semi-structured focus group interviews (approximately one hour in duration) with each of the three groups. Introductory material sourced from each group's website provided basic information about the ensemble and its evolution. As a phenomenological qualitative case study this research sought in-depth understandings of the participants. Phenomenological research entails an exploration of participants' lifeworlds, experiences, understandings, and perceptions (Brocki \& Wearden, 2006; Reid, Flowers \& Larkin, 2005) and recognizes that this involves a process of interpretation by the researcher (Smith, 2005; Clarke, 2009). Giorgi and Giorgi (2003) emphasize that it is important to "remain as faithful as possible to the phenomenon and to the context in which it appears in the world" (28). The Research Assistant undertook the interviews that were audio recorded and transcribed. All participants were invited to confirm the accuracy of the interview transcript. The questions initially sought details about the individual participants, their involvement with the ensemble, and their understandings of group membership. It must be recognised that the older participants for this project have been sought because of their membership of singing ensembles. All informants have remained in their ensembles and were happy to talk about what membership of their respective groups meant to them. It is recognised that this sample is limited in that they are representative of people who have chosen to share music and culture in a small social group and who interpret this as a positive aspect of their lives.

The data were analysed using Interpretative Phenomenological Analysis (IPA), which is a "qualitative research approach committed to the examination of how people make sense of their major life experiences" (Smith, Flowers \& Larkin, 2009: 1). IPA is phenomenological in that it "seeks an insider perspective on the lived experiences of individuals" and acknowledges that, as the primary analytical instrument, the researchers' beliefs "are not seen as biases to be eliminated but rather as being necessary for making sense of the experiences of other individuals" (Fade, 2004, p. 648). In-depth, conversational semi-structured interviews are considered the most effective data collection strategy in IPA (Smith, 2005; Eatough \& Smith, 2006). The interview data are analysed and reported thematically, then illustrated by direct quotations from the transcripts (Larkin, et al., 2006). Quotations can amplify themes and reveal differing perspectives of interviewees (Tzanidaki \& Reynolds, 2011). The data were analysed under a broad theme of perceived benefits to the individual ensemble members that included physical, cognitive and emotional well-being, and validation through belonging and sharing community.

\section{The three case studies}

To contextualise the data generated by the three case studies we will briefly introduce each music group: the Coro Furlan, the Bosnian Behar Choir and the Skylarkers.

\section{The Coro Furlan}

The Coro Furlan is the only male Italian choir remaining in Melbourne, Australia. The choir was formed in 1975 by a group of Italian singers under the experienced direction of conductor Gianpietro Canil. The choir's repertoire consists mainly of songs from the Italian region of Friuli in the local language, Friulano, as they see themselves as the custodians of this cultural heritage. The choir also sings songs in the Veneto dialect, and Italian, English, and Latin languages. Their repertoire includes popular English language songs such as Battle 
Hymn of the Republic, I am Australian and You'll never walk alone and Italian songs such as La Montanara, Sul Ponte Di Bassano, and Va Pensiero (Coro Furlan, 2011). Membership of the choir is open to men who must love singing Italian music "regardless of race and background" (Coro Furlan, 2011). There is no audition to join nor is there an expectation of the ability to read music or sight sing. The Coro Furlan practices weekly. At the time of interview the choir consisted of twenty-two members. They sing in four parts both accompanied and unaccompanied. The choir has a uniform and follows its own 'Ten Commandments', first written in the 1970s, that reflect their strong sense of community and their commitment to choir membership (Southcott \& Joseph, 2013).

\section{The Bosnian Behar Choir}

The Bosnian Behar (meaning Blossom) Choir was formed in 1998 at a picnic that may explain the name of the choir. This mixed choir has a small but dedicated membership, mostly Bosnian with a few Croatians. At the time of interview all members were over the age of 50 . The majority of the members (90\%) were refugees who came from Bosnia, having lost everything. There were a greater number of women than men. There is no audition to join the choir that rehearses weekly and is run by a formal committee. The Bosnian choir promotes Bosnian cultural heritage through participation in events and performances. This small choir is actively involved in the community and has taken part in more than one hundred community events. These have included the Match Works Pako Festa, Brimbank Festival, Geelong Festival, Bosnia-Herzegovina Festival, and the Multinational Concert Bushfire Appeal. The members of the choir are committed to its continuance and expect members to make a real commitment to the group. If more than four rehearsals are missed without apology, then membership is cancelled (Southcott \& Joseph, 2009).

\section{The Skylarkers}

Initially the Skylarkers were formed as a four-part choir in 1999 in a suburb of Melbourne, Victoria. In time the nature of the choir and its membership has changed under subsequent music directors. Since 2009 the current music director has focused on music theatre repertoire and employs a style consistent with this genre that combines songs, spoken dialogue, and dance. The choir membership has remained constant at about fifteen but the balance of voices has changed from equal representation to a pre-dominance of women. The interviewed members of the group refer to themselves as performers and singers. There is no audition, or expectation of music literacy, and there is a small membership fee. The choir rehearse weekly and performs about twenty shows per year. This group that comprises retirees of up to 90 years old considers itself more a music theatre-performing group than a choir per se. They perform for a range of community including Senior Citizens' Clubs, Hospitals, Hostels, Nursing homes, and Retirement Villages. The choir is organised by an elected committee and the music director takes most of the responsibility for the program that consists of group numbers and solo items. On stage the choir has a dress code.

\section{The findings}

The findings identified a number of different ways in which participation in the singing groups could benefit the individual members. As a corollary of this, members pointed out 
what they were able to share with their local communities. We have chosen only those elements that are addressed by all three cases and illustrated these with verbatim quotations. Benefits for individuals were identified as an enhanced sense of personal well-being that included physical, cognitive, and emotional aspects. Participants also described how membership of the ensemble provided a way to gain a sense of personal validation that included belonging to a group and being able to share culture, heritage and memory with each other, families, and members of their local community.

\section{Individual well-being}

Amongst all the participants well-being is generally discussed under the headings physical, cognitive and emotional well-being. While enhanced physical well-being was not stressed by the interviewees, several made general comments that relate to physical health such as the following statement by a member of the Coro Furlan, "It's good for us; we are all getting older ... it is also good for my body". Hays (2005) confirmed that some of his participants "felt music had the effect of restoring and rejuvenating their energy levels" (p. 30). One person from the Skylarkers specifically mentioned that at his annual medical check-up his lung capacity had improved and ascribed that to learning to "breathe from the diaphragm when singing". Participants also connected physical well-being to longevity. A member of the Coro Furlan stated "I want to sing with the Choir for as long as I can". All case studies showed that participants linked group membership to an improved attitude to illness. A member of the Behar Choir described past experiences when "some of our members have been quite ill or had an operation. They can't wait to get back to rehearsals. They feel that coming to choir will make them better sooner than staying at home thinking about how unwell they are". Another member of the same choir explained that,

\section{Whatever makes you happy and makes you feel better that's well-being. You may be ill ... and this [singing] may help you to feel better ... all of a sudden you start to sing and you think, 'Oh gosh, I feel good.}

Anna felt empowered by this as "you create your own sense of well-being, nobody can do it for you". In her study of elderly Swedish women Forssén (2007) also identified that music engagement offered comfort, survival, enjoyment, and a breathing space in daily life.

Participants identified a number of specific ways in which membership of the ensemble was beneficial to their cognitive well-being. The oldest member of the Coro Furlan explained that being in the ensemble "helps my mind a lot to remember these songs and sing them again" and reiterated that, the "choir helps me a lot in my mind". A member of the Skylarkers thought that learning new things sharpened her memory. Her partner cited his guitar teacher's explanation that as you learn new things, new connections are made in your brain and that, although

$$
\begin{aligned}
& \text { it might take a day or two for that connection to be made... a couple of days later you'll } \\
& \text { go through it again and you'll find you can do it better! This is because 'things' are } \\
& \text { connecting! So, maybe that's what happens when we learn the words of new songs. }
\end{aligned}
$$

The many cognitive benefits older adults derived from music engagement included improved concentration and memory, a sense of achievement in acquiring new skills and knowledge as well as a recognition of maintained mental agility (Creech, et al., 2013a, p. 10).

Emotional well-being was emphasised by all participants in all three case studies. For example a member of the Coro Furlan stated, "I like the singing; my wife also likes me being 
in the choir because when things don't look too good I start singing and we are happy!" Rehearsals were seen as uplifting events in themselves. A member of the Behar Choir asserted that singing "recharges my batteries!" He added, "if I'm upset about something or am feeling a little worried, when I get to rehearsal and sing I feel much better - the problems seem to go away". Creech et al. (2013b) reported a range of subjective potential contributions from group music making including positive emotional responses, enjoyment and social affirmation in the lives of older people. Self-confidence is another aspect of emotional wellbeing that emerged from the analysis of the case studies. A member of the Skylarkers described his preparedness to "have a go" at challenges he would once have avoided. Engagement with community arts practices can provide participants with feelings of strength, comfort, higher self-esteem and a space for voices to be heard (Forssén, 2007).

In discussing their membership of a community music group participants likened the group to a family. For example, when one of the members of the Behar Choir (Anna) first joined she felt that membership of the choir could replace lost family. She said, "I was really touched by some of the things the members do - somebody may be sick and members visit them". This made her feel less isolated and gave her a greater sense of belonging. Noticing "other people feeling the same way" meant a lot to her as it validated her feelings. Anna perceived that, "in our group we are not just from the same country, we are not just friends, we really are family!" A similar sense of familial engagement was described by members of the Coro Furlan who enjoy, "a sense of camaraderie, jokes and friendship" (Coro Furlan, 2011). One member of the Coro Furlan focused his sense of family to relationships between male family members. He stated that,

$$
\begin{aligned}
& \text { one of the things I like about the choir is the sense of togetherness we have. I look on these } \\
& \text { guys as my uncles; I've only got one uncle in Australia. These guys are older than me and } \\
& \text { being in the choir is a cultural event I can enjoy. }
\end{aligned}
$$

For some participants finding this new 'family' replaced absent children. One participant specifically stated, "when the family left I couldn't go back into that empty nest". This was the point at which she joined a community music ensemble seeking a sense of connectness that is identified by Baker and Ballantyne (2013) as "integral to a meaningful life" (p. 19).

\section{Validation through belonging and sharing}

All participants identified the importance of gaining a sense of validation through belonging to their particular ensemble. Having a sense of purpose has been described by older people as "core components of their health and well-being" (Heaven, et al., 2013, p. 224). Encapsulating this idea, Anna from the Behar Choir asserted that, "being a choir member gives me a purpose in life". Underpinning all three groups' engagement with their ensembles is a desire to contribute to the community, which was realized through audience responses to their performances. A member of the Skylarkers explained that, "we are entertaining other people, it is good to think that we are doing something to help somebody else ... I just wanted to bring joy into the lives of others". The participants all stressed that by performing with their respective groups they gained a sense of purpose as they could bring music and pleasure to their audiences. Silvey (2001) similarly identified the potential for sharing music with others to add meaning to the experience for the performers. For all the groups, it appeared to be essential that they felt appreciated by their audiences. A member of the Coro Furlan discussed how, after a concert, members of the audience approached them with "tears in their eyes" as they "were really moved by the songs". Participants reported that they felt 
that they had established an almost tangible connection with their audiences. A member of the Behar Choir stated,

$$
\begin{aligned}
& \text { it's almost as if the people listening come together, for a short time they are part of } \\
& \text { something, even though they don't really belong to the group, for that particular moment } \\
& \text { they do belong to the group as they listen to the music and enjoy it. That's the sense of } \\
& \text { satisfaction I get out of being a choir member. }
\end{aligned}
$$

The meaningful engagement between performers and audiences offers a range of benefits to all (Bryant, et al., 2001) and enhances a sense of self-worth and purpose amongst the members of community music ensembles.

In some ways all three groups believe in sharing their heritage, history and culture but two of the groups, the Coro Furlan and the Bosnian Behar Choir also bring a sense of dual cultural and linguistic identity. The members of both these groups have a very strong sense of their regional and cultural identity framed within their sense of being Australian. A member of the Behar Choir stated that, "as Bosnian or Croatian Australians we are all Australians. I am proud to be an Australian; they help us heaps but I believe we help them too". Members of the Coro Furlan recounted the power of the old traditional songs from their past in Friuli and described a reaction by a fellow countryman to one of their performances, "sometimes when we sing in Friulan there may be a returned soldier from the war in the audience who cries a little bit. It makes you feel like crying yourself. There's something there [in the music and] It's wonderful!" The notion of embracing cultural heritage and sharing it with others is a powerful motivator for continued engagement.

Some of the groups see themselves as cultural ambassadors with the mission to preserve and promote their culture and language. A member of the Coro Furlan explained, "culturally, I'm an Italian and through the choir and its older members I can learn more about my culture, I can enjoy it, experience it and pass it on to future generations". Similarly, members of the Behar Choir perceive themselves to be both Bosnian and Australian and singing in the choir connects them to their Bosnian heritage by the performance of songs in their original language. One member stated that he has been in Australia for about forty years and enjoys living here but singing in the choir "takes me back to those days, it brings me memories ... and there are still some ties with the old lifestyle". Thus the two culturally and linguistically diverse choirs uphold their past and maintain their cultural heritage. Further the choir connects its members to their place in contemporary Australia and allows them to share their culture with their families, friends and the wider community. Choir members stressed that sharing music with the broader contemporary Australian community enables the sharing of cultural heritage and the celebration of diversity. Writing about shared community music making, Messenger (2013) asserts that the "community grows through sharing" (pp. 178179).

This nostalgic desire to share memory also appears within mono-cultural groups such as the Skylarkers as one member recounted,

Last week we did a concert and there was a woman in a long bed who was very oldshe was in her 90s. Our last number is always chosen to relate to the age group of the audience. For this concert we chose You are my sunshine' and as soon as we started to 
sing she started to clap. She was obviously very unwell and two nurses ran right round the back [astounded] as she was clapping.

The performances of the Skylarkers are intended to provoke nostalgic reactions in their audiences. The songs that particularly evoked strong links to their past were, as one described, the "songs from our childhood. We wanted to keep the memories of those days alive. We didn't want to forget them". This resonates with the Coro Furlan who saw singing old school songs as a way of reclaiming past memories and strengthening their cultural identity. Hays, Bright and Minichiello (2002) also identified the emotional release that could be engendered through the sharing of memories and music making that can trigger "joy, sorrow, happiness, or pleasant memories" (p. 169).

\section{Discussion and conclusion}

All three music groups are cognisant of the myriad benefits of singing and performing together. As discussed these benefits included an enhanced sense of personal well-being and membership of the singing ensembles provided a way for participants to gain a sense of personal validation by belonging to a group and sharing culture, heritage and memory with each other and members of their local community. The verbatim quotations from participants illustrate the power of music to change individual lives which is encapsulated in the quotation already cited, "all of a sudden you start to sing and you think, 'Oh gosh, I feel good". Occasionally individuals mentioned what they defined as particular physical and cognitive benefits. The former include better lung capacity and the latter include improved memory and ability to learn. The comments from most participants addressed emotional well-being that included gaining increased self-confidence, a more positive attitude to life, gaining a sense of belonging and feeling as if they were part of an extended family. Membership of all the groups continues to be fluid reflecting the members' changing life circumstances but each group has proved itself to be resilient and ongoing. This was encapsulated by one of the Skylarkers who said, "the show must go on". Such group continuance is strongly tied to the sense of family that develops and manifests in a palpable sense of connectedness and caring within the group. This resonates with the findings of Bailey and Davidson (2005, p. 277) who identified that the "camaraderie experienced in the choir setting results in social encounters which are indicative of relationships and feelings normally experienced with family and friends". Additional benefits to the individual were identified by members of all three groups who gained a sense of purpose and fulfilment from membership of their respective ensembles that aligns with the wide range of findings reported by Macdonald (2013).

Similarly, all groups recounted the benefits and meaning of community engagement that was a result of membership of the ensemble. For all participants the relationship between the group and their audiences was paramount with interviewees describing at length emotionally charged moments with their audiences where there were tears, dancing, and sing-alongs. These responses moved the ensemble members and validated their continued contribution to their communities. Shared music making by the three music ensembles in this study offers both the members and their audiences a sense of rejuvenation, pleasure, and musical enrichment. This understanding aligns with consistent research that identifies the emotional and social benefits from a "sense of shared fun and enjoyment, having a sense of purpose, confidence and empowerment" (Creech, et al., 2013b, p. 40). The performances of all 
ensembles evinced nostalgia amongst themselves and their audiences but for two of the groups discussed in this article their sense of sharing culture, language, and heritage was particularly important. Members of both the Behar Choir and the Coro Furlan spoke about performing in first language and the importance of maintaining and transmitting their traditional cultures both to younger generations and the wider contemporary, diverse, multicultural Australian community. These choirs are amongst the many such community ensembles formed by older people that demonstrate how the combination of ageing, music and culture can generate a sense of belonging and fulfilment (Joseph, 2009; Li \& Southcott, 2012).

The three phenomenological case studies highlight the personal, musical and social benefits of singing together and sharing music making for members of the ensembles and their belief in the importance of sharing music making with their local Australian community. The findings of these studies illuminate the contribution of music making to overall well-being amongst older people (Skingley \& Bungay, 2010; Creech, et al., 2013a; Macdonald, 2013). With ageing populations across the globe provision of opportunities for older people to remain active and engaged in communities is essential. Greaves and Farbus (2006, p. 135) underlined the role of "active social network building" that empowers participants, supports the formation of friendships and enhances resilience. As discussed, these three groups demonstrate resilience, perseverance and a sense of personal fulfillment. Participation in community music making offers our participants a place and space for social belonging, sharing, enjoyment, personal development, and empowerment (Coffman, 2002a, 2002b; Sixsmith \& Gibson, 2007). The groups discussed here are not unique but reflect and exemplify the practices of many such music groups who remain active, positive and optimistic. Active music making in community choirs and music ensembles offers an "anchorage to life" (Borglin et al., 2005, p. 205) and continues to be an effective way to support individuals' well-being, build community with each other, and share culture and heritage.

\section{References}

Anetzberger, G.J. (2002). Community resources to promote successful ageing. Clinics in Geriatric Medicine. 18, 611-625.

Ashman, A. (2008). Contemporary cultures and education. In A. Ashman \& J. Elkins (Eds.), Education for Inclusion and Diversity (pp. 3-34). New South Wales: Pearson Education Australia.

Australian Bureau of Statistics (2013a). Population Clock. Retrieved from http://goo.gl/rKOgS

Australian Bureau of Statistics (2011). Population by Age and Sex, Australian States and Territories, Jun [sic] 2010. Retrieved from http://goo.gl/Jw9HV

Australian Bureau of Statistics (2013b). Release. Retrieved from http://goo.g1/y53W7d

Australian Government Department of Health and Ageing (2012). National ageing and aged care strategy for people from culturally and linguistically diverse (CALD) backgrounds. Canberra: Commonwealth of Australia. 
Bailey, B.A. \& Davidson, J.W. (2005). Effects of group singing and performance for marginalized and middle-class singers. Psychology of Music, 33(3), 269-303.

Baker, F.A. \& Ballantyne, J. (2013). "You've got to accentuate the positive": Group songwriting to promote a life of enjoyment, engagement and meaning in ageing Australians. Nordic Journal of Music Therapy, 22(1), 7-24.

Borglin, G., Edberg, A-K., \& Hallberg, I.R. (2005). The experience of quality of life among older people. Journal of Ageing Studies, 19(2005), 201-220.

Brocki, J.M. \& Wearden, A.J. (2006). A critical evaluation of the use on interpretative phenomenological analysis (IPA) in health psychology. Psychology and Health, 21(1), $87-108$.

Bryant, L.L., Corbett, K.K. \& Kutner, J.S. (2001). In their own words: a model of healthy ageing. Social Science and Medicine. 53, 927-941.

Chen, Y. \& Feeley, T.H. (2013). Social support, social strain, loneliness, and well-being among older adults: An analysis of the Health and Retirement Study. Journal of Social and Personal Relationships, 31(2), 141-161.

Chené, A. \& Sigouin, R. (1995). Never old older learners. International Journal of Lifelong Education, 14(6), 434-443.

Clarke, C. (2009). An Introduction to Interpretative Phenomenological Analysis: a Useful Approach for Occupational Therapy Research. British Journal of Occupational Therapy, 72(1), 37-39.

Clift, S.M. \& Hancox, G. (2001). The perceived benefits of singing: findings from preliminary surveys of a university college choral society. The Journal of the Royal Society for the Promotion of Health, 121(4), 248-256.

Clyne, M. \& Kipp, S. (2006). Australia's community languages. International Journal of the Sociology of Language, 180, 7-21.

Coffman, D.D. (2002a). Banding Together: New Horizons in Lifelong Music Making. Journal of Ageing and Identity, 7(2), 133-143.

Coffman, D.D. (2002b). Music and quality of life in older adults. Psychomusicology, 18, 7688.

Cohen, A., Bailey, B. \& Nilsson, T. (2002). The importance of music to seniors. Psychomusicology, 18, 89-102.

Coro Furlan (2011). Coro Furlan. Retrieved from http://goo.gl/W03RJ4

Cramm, J.M., van Dijk, H.M., \& Nieboer, A.P. (2012). The Importance of Neighborhood Social Cohesion and Social Capital for the Well Being of Older Adults in the Community. The Gerontologist, 53(1), 142-150.

Creech, A., Hallam, S., McQueen, H. \& Vargarigou, M. (2013a). The power of music in the lives of older adults. Research Studies in Music Education, published online.

Creech, A., Hallam, S., Vargarigou, M., McQueen, H. \& Gaunt, H. (2013b). Active music making: a route to enhanced subjective well-being among older people. Perspectives in Public Health, 133(1), 36-43. 
Department of Foreign Affairs and Trade, Australian Government (2013). About Australia. Retrieved from http://goo.gl/vLhrU

Eatough, V. \& Smith, J. (2006). 'I was like a wild wild person': Understanding feelings of anger using interpretative phenomenological analysis. British Journal of Psychology, 97, 483-498.

Escuder-Mollon, P. (2012). Modelling the impact of lifelong learning on senior citizens' quality of life. Procedia - Social and Behavioral Sciences, 46(2012), 2339-2346.

Fade, S. (2004). Using interpretative phenomenological analysis for public health nutrition and dietetic research: a practical guide. Proceedings of the Nutrition Society, 63(4), 647653.

Forssén, A.S.K. (2007). Humour, beauty, and culture as personal health resources: Experiences of elderly Swedish women. Scandinavian Journal of Public Health, 35(3), 228-234.

Giorgi, A. \& Giorgi, B. (2003). Phenomenology. In J.A. Smith (Ed.) Qualitative Psychology: A practical guide to research method (pp. 25-50). London: SAGE publications.

Greaves, C.J. \& Farbus, L. (2006). Effects of creative and social activity on the health and well-being of socially isolated older people: outcomes from a multi-method observational study. The Journal of the Royal Society for the Promotion of Health, 126(3), 134-142.

Hays, T. (2005). Well-being in Later Life through Music. Australasian Journal on Ageing, 24(1), 28-32.

Hays, T., Bright, R. \& Minichiello, V. (2002). The Contribution of Music to Positive Ageing: A Review. Journal of Ageing and Identity, 7(3), 165-75.

Heaven, B., Brown, L.J.E., White, M., Errington, L., Mathers, J.C., \& Moffatt, S. (2013). Supporting Well-Being in Retirement through Meaningful Social Roles: Systematic Review of Intervention Studies. The Milbank Quarterly, 91(2), 222-287.

Huxhold, O., Fiori, K.L., \& Windsor, T.D. (2013). The Dynamic Interplay of Social Network Characteristics, Subjective Well-Being, and Health: The Costs and Benefits of Socio-Emotional Selectivity. Psychology and Ageing, 28(1), 3-16.

Huxhold, O., Miche, M., \& Schüz, B. (2013). Benefits of having friends in older ages: differential effects of informal social activities on well-being in middle-aged and older adults. Journals of Gerontology, Series B: Psychological Sciences and Social Sciences, 69(3), 366-375.

Jacob, C., Guptill, C. \& Sumsion, T. (2009). Motivation for continuing involvement in a leisure-based choir: The lived experiences of university choir members. Journal of Occupational Science. 16(3), 187-193.

Joseph, D. (2009). Sharing music and culture through singing in Australia. International Journal of Community Music, 2(2/3), 169-181.

Lally, E. (2009). 'The power to heal us with a smile and a song': Senior Well-being, Musicbased Participatory Arts and the Value of Qualitative Evidence. Journal of Arts and Communities, 1(1), 25-44. 
Larkin, M., Watts, S. \& Clifton, E. (2006). Giving voice and making sense in interpretative phenomenological analysis. Qualitative Research in Psychology, 3, 102-120.

Li, Sicong \& Southcott, J. (2012). A Place for Singing: Active Music Engagement by Older Chinese Australians. International Journal of Community Music, 5(2), 59-78.

Macdonald, R.A.R. (2013). Music, health, and well-being: A review. International Journal of Qualitative Studies in Health and Well-being, 8, 1-13.

Messsenger, S.J. (2013). Digital Communities: Sharing, Teaching, Exploring. In K.K. Veblen, S.J. Messenger, M. Silverman, \& D.J. Elliott (Eds.), Community Music Today (pp. 169-181). Lanham, Maryland: Rowman \& Littlefield Education.

Reid, K., Flowers, P., \& Larkin, M. (2005). Interpretative phenomenological analysis: An overview and methodological review. The Psychologist, 18, 20-23.

Silvey, P.E. (2001). Perspectives of Ageing Adult Choral Musicians: Implications for Meaningful Lifelong Participation in Ensemble Singing. The Phenomenon of Singing, 1, 199-218.

Sixsmith, A. \& Gibson, G. (2007). Music and the wellbeing of people with dementia. Ageing and Society, 27(1), 127-145.

Skingley, A. \& Bungay, H. (2010). The Silver Song Club Project: singing to promote the health of older people. British Journal of Community Nursing, 15(3), 135-140.

Skingley, A., Clift, S.M., Coulton, S.P. \& Rodriguez, J. (2011). The effectiveness and costeffectiveness of a participative community singing programme as a health promotion initiative for older people: protocol for a randomised controlled trial. BMC Public Health, 11(142). Retrieved from http://goo.g1/OiyKQQ

Smith, J.A. (2005). Jonathon A. Smith [Online]. Retrieved from http://www.psyc.bbk.ac.uk/people/academic/smith/smith_j/js.html

Smith, J.A., Flowers, P. \& Larkin, M. (2009). Interpretative Phenomenological Analysis. Theory, Method and Research. London: Sage.

Southcott, J. \& Joseph, D. (2013). Community, commitment, and the Ten Commandments: Singing in the Coro Furlan. International Journal of Community Music, 6(1), 79-92.

Southcott, J. and Joseph, D. (2009). Sharing community through singing: The Bosnian Behar Choir in Victoria, Australia. e-journal of Studies in Music Education, 8(2), 17-27.

Tzanidaki, D. \& Reynolds, F. (2011). 'Exploring the meanings of making traditional arts and crafts among older women in Crete, using interpretative phenomenological analysis'. British Journal of Occupational Therapy, 74(8), 375-382.

World Health Organisation (2002). Active ageing: A policy framework. Retrieved from http://goo.g1/5R93i

World Health Organization (2012). Good health adds life to years: Global brieffor World Health Day 2012. Geneva, Switzerland: World Health Organization. 